\title{
High energy feeding in small for gestation infants
}

\author{
O G BROOKE AND J M KINSEY
}

Department of Child Health, St George's Hospital Medical School, London

SUMMARY Seventeen low weight infants with symmetrical growth retardation (no wasting) were entered in a randomised, double-blind comparison of high energy, $3.6 \mathrm{MJ} / \mathrm{L}(87 \mathrm{kcal} / 100 \mathrm{ml}) v$ standard energy $2.7 \mathrm{MJ} / \mathrm{L}(65 \mathrm{kcal} / 100 \mathrm{ml})$ feeds given ad libitum during their first three months. Intakes were measured throughout, and energy absorption was determined at home from balance studies at 6 weeks and 3 months of age. Infants on high energy feeds absorbed the same proportion of energy intake but consumed less feed throughout the study. Regulation of feed intake was such that by 2 months of age energy intakes were similar in both groups, though before this time infants on high energy feeds had a higher net energy intake and grew slightly faster. Appetite regulation seems to be present at birth or soon after but is not fully developed for several weeks, and until this time increased energy intake can be imposed by adjusting the energy density of the feed.

Small for gestational age infants form the underprivileged section of the neonatal population in terms of growth. Though these small infants, about $10 \%$ of all births, undoubtedly include many who have been affected by a restrictive intrauterine influence such as placental insufficiency, most have no clear cause for their small size. Presumably these babies have a genetic reason for being small and often do not achieve supranormal (catch up) growth in early infancy, thus remaining at the bottom end of the growth curves. ${ }^{1}$ Small babies cause their mothers anxiety, and when they become small adults may suffer social and reproductive disadvantages. It would be of potential value, therefore, to achieve accelerated growth in infancy in these subjects, in the hope that this would pave the way towards a more nearly average adult size. With this in mind, a study was designed to investigate the effect of increasing the energy density of the diet of a group of small for gestational age infants. This paper reports the effects of such a diet on spontaneous food intake.

\section{Subjects and methods}

Infants. Seventeen infants who were small for gestational age were studied with their parents' consent. These infants were unavoidably selected in that their mothers did not wish to breast feed them, and a further, deliberate selection was made in that none was underweight due to obvious wasting, confirmed by weight and length ratios and arm anthropometry ${ }^{2}$ (in no case was any measurement more than 2 SD below the mean for our term infant population). Infants underweight because of wasting were not studied since they generally show good catch up growth. Infants entering the study were randomly allocated to one of two formula milks (see below), which were fed from the second week of life. No infant failed to complete the study. The allocated formula was supplied in ready to feed form, identified by number only, and was given ad libitum for three months. During this period no other feeds were offered. The study was double blind and the randomisation and supply logistics were carried out by a nutritionist working for the infant food manufacturing company which supplied the formulas (Milupa Ag). Details of the infants are given in Tables 1 and 2. The study had ethical approval.

Formula milks. The two formulas are designated standard energy formula, $2.7 \mathrm{MJ} / \mathrm{L}(65 \mathrm{kcal} / 100 \mathrm{ml})$, and high energy formula $3.6 \mathrm{MJ} / \mathrm{L}(87 \mathrm{kcal} / 100 \mathrm{ml})$. The composition of the major nutrients is given in Table 3. The higher energy content of the latter formula was provided by both fat and carbohydrate (maltodextrins). Protein and mineral content were increased commensurate with the increased energy.

\section{Experimental details and measurements}

Feed intake

Since the feeds were given in ready to feed form 
Table 1 Details of the infants studied

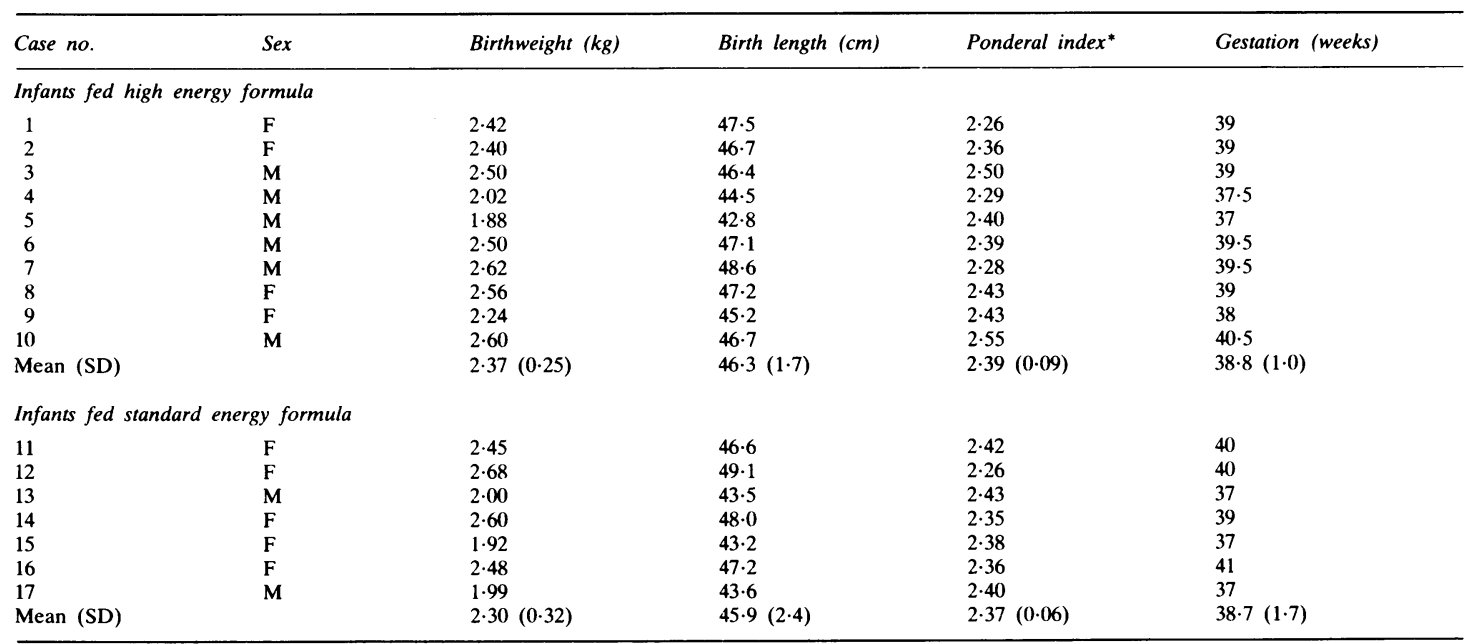

${ }^{*}$ Ponderal index $=\frac{\text { wt }(\mathrm{g})}{\text { length }^{3}}(\mathrm{~cm}) \times 100($ mean $(\mathrm{SD})$ for term infant population=2.65 SD $(0 \cdot 20))$.

Table 2 Evidence for lack of wasting in infants studied (results mean (SD))

\begin{tabular}{llll}
\hline & $\begin{array}{l}\text { High energy } \\
\text { formula group }\end{array}$ & $\begin{array}{l}\text { Standard energy } \\
\text { formula group }\end{array}$ & $\begin{array}{l}\text { Normal infants } \\
\text { (both sexes combined) }\end{array}$ \\
\hline Mid-upper arm circumference $(\mathrm{cm})$ & $9 \cdot 9(0 \cdot 5)$ & $9 \cdot 8(0 \cdot 5)$ & $10 \cdot 8(0 \cdot 8)$ \\
Triceps skinfold $(\mathrm{mm})$ & $3 \cdot 5(0 \cdot 5)$ & $3 \cdot 4(0 \cdot 6)$ & $3 \cdot 8(0 \cdot 6)$ \\
Arm fat area $\left(\mathrm{cm}^{2}\right)^{*}$ & $1 \cdot 94(0 \cdot 35)$ & $1 \cdot 93(0 \cdot 27)$ & $1 \cdot 97(0 \cdot 41)$ \\
Maximum calf circumference & $10 \cdot 7(0 \cdot 6)$ & $10 \cdot 6(0 \cdot 6)$ & $11 \cdot 5(1 \cdot 0)$ \\
Ponderal index & $2 \cdot 39(0 \cdot 09)$ & $2 \cdot 37(0 \cdot 06)$ & $2 \cdot 65(0 \cdot 20)$ \\
\hline
\end{tabular}

*For methods of calculation see Brooke et al $(1981)^{2}$ and Table 1.

Table 3 Composition of formulas (per litre)

\begin{tabular}{lll}
\hline & $\begin{array}{l}\text { High energy } \\
\text { formula }\end{array}$ & $\begin{array}{l}\text { Standard energy } \\
\text { formula }\end{array}$ \\
\hline Energy & & \\
$\quad$ (Kcal) & 870 & 650 \\
(MJ) & $3 \cdot 77$ & $2 \cdot 72$ \\
Protein (g) & 23 & 15 \\
Protein energy (\%) & 10 & $9 \cdot 2$ \\
Fat (g) & 42 & 36 \\
Carbohydrate (g) & 107 & 72 \\
Sodium (mg) & 350 & 180 \\
Calcium (mg) & 800 & 570 \\
Phosphorus (mg) & 550 & 350 \\
\hline
\end{tabular}

from one batch their composition was constant. Intake measurements were therefore obtained with considerable accuracy from the volumetric measurement of unconsumed feeds, which were retained for this purpose throughout the study. None of the infants suffered serious vomiting. Small possets were ignored. During measurements of digestible energy (see below) intake was measured as accurately as possible by weighing feed bottles before and after feeding. The energy density of the feeds was determined at the end of the study by bomb calorimetry. ${ }^{3}$

\section{Measurement of digestible energy}

The digestible energy is the difference between the energy intake and the faecal energy. Thus it represents energy absorption. Energy digestibility was studied to ensure that there was no malabsorption of high energy formula. It was measured at 6 weeks and 3 months in all infants except one (case 16), whose mother could not manage the procedures. These involved the accurate measurement of feed intake and the collection of stools over three days:

Intake. This was determined by weight of feed consumed, the bottles being preweighed by the research nurse and reweighed after feeds. The mother retained all feed bottles, even if completely 
emptied, and labelled them with the date and time of the feed. The research nurse visited daily to collect used bottles for weighing and to ensure that none had been forgotten or discarded.

Faecal losses. All faeces were collected in nappy liners over three days between carmine markers. The collection was done by the mother who was provided with all the necessary nappies, liners, and labelled polythene bags. A small freezer was taken to her house for the period of the collection and stools, parcelled in their nappy liners and sealed in polythene bags, were frozen at $-24^{\circ} \mathrm{C}$. The stools were subsequently weighed, aggregated in 24 hour lots, freeze dried, and measured for energy content by bomb calorimetry.

With the aid of daily visiting and simple illustrated written instructions, 16 of the mothers were able to complete the collections satisfactorily.

\section{Anthropometry}

All infants were measured weekly at home by the research nurse. The following measurements were made: Weight, to the nearest $10 \mathrm{~g}$ on a portable beam balance; crown to heel length, to the next succeeding $1 \mathrm{~mm}$ on a stadiometer; upper arm length, from the acromion to the olecranon with a caliper; occipitofrontal head circumference; midupper arm circumference; maximum calf circumference; lower abdominal circumference, to the next succeeding $1 \mathrm{~mm}$ using paper tape; and triceps, biceps, and subscapular skinfold thickness, ${ }^{4}$ to the next succeeding $0.1 \mathrm{~mm}$ using a Herpenden caliper. Growth comparisons were made after correction for gestational age. To allow for sexual differences in growth rates, weight, length, and head circumference were also compared as a percentage of mean growth velocity over the same postnatal time period, using Gairdner's standards. ${ }^{5}$

\section{Plasma osmolality}

Capillary blood was taken on one occasion at 6 weeks of age for measurement of osmolality in all infants. Measurements were performed on a Wescor micro-osmometer.

Statistical analysis. The results were compared by analysis of variance using Snedecor's F test.

\section{Results}

All 17 infants completed the study. Ten received a high energy and seven a standard energy formula (Table 1). There was no significant difference in their birth size or gestational age.

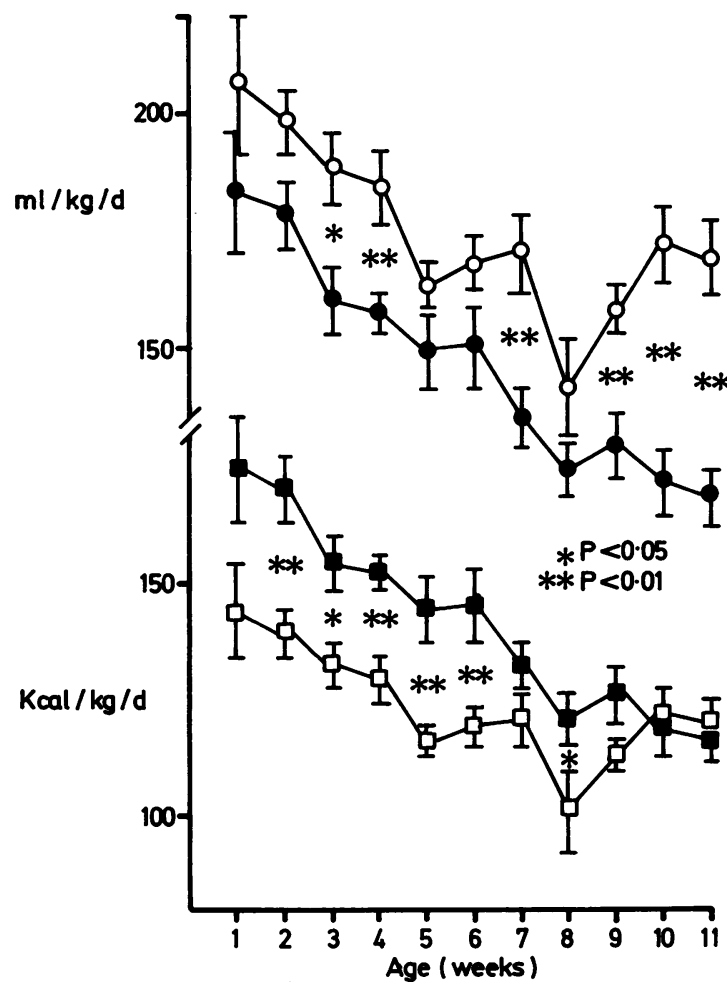

Figure Feed intake and energy intake from week 1 to week 12 in infants fed high energy (HEF) and standard energy (SEF) formulas (means (SEM)).

Feed intake $(\mathrm{m} / \mathrm{kg} / \mathrm{d})$, $\longrightarrow=\mathrm{HEF}, \mathrm{O}-\mathrm{O}=\mathrm{SEF}$. Energy intake $(\mathrm{Kcal} / \mathrm{kg} / \mathrm{d}) \square=\mathrm{HEF}, \square-\square=\mathrm{SEF}$.

Conversion-traditional units to $S I$ : energy $1 \mathrm{kcal} / \mathrm{kg} \approx 0.04 \mathrm{MJ} / \mathrm{kg}$.

Food intake. The Figure shows food volume and energy intakes per $\mathrm{kg}$ body weight during the study period. Infants receiving high energy formula consumed less feed than those receiving standard formula, the difference reaching significance in weeks $3,4,7,9,10$, and 11 . The reduction in intake by the high, energy formula group did not fully compensate for the increased energy density of the formula, so that the energy intakes of these infants were significantly greater in the early weeks of the study than those on standard formula. By the seventh week and thereafter, full compensation had occurred and the energy intakes of the two groups were no longer significantly different.

Digestible energy. Table 4 shows the results of the determinations of digestible energy on the two formulas during weeks 6 and 12. Digestibility was high on both formulas and there was no significant difference between them. 
Table 4 Data on feed volume and energy intake in infants on high energy and standard energy feeds (measurements made over 3 days, results mean $(S D)$ )

\begin{tabular}{|c|c|c|c|c|}
\hline \multirow{3}{*}{ Daily feed intake $(\mathrm{ml} / \mathrm{kg})$} & \multicolumn{2}{|c|}{ High energy formula $(n=10)$} & \multicolumn{2}{|c|}{ Standard energy formula $(n=7)^{*}$} \\
\hline & 6 weeks: & $158(31)$ & $\mathrm{p}<0.01$ & $193(20)$ \\
\hline & 3 months: & $115(22)$ & $\mathrm{p}<0.001$ & $164(32)$ \\
\hline Daily energy intake $(\mathrm{Kcal} / \mathrm{kg})$ & 3 months: & $100(19)$ & NS & $100(21)$ \\
\hline \multirow[t]{2}{*}{ Faecal energy (KcaVday) } & 6 weeks: & $63(37)$ & NS & $41(25)$ \\
\hline & 3 months: & $42(20)$ & NS & $37,19)$ \\
\hline Digestible energy (Kcal/kg) & 6 weeks: & $121(24)$ & NS & $116(14)$ \\
\hline
\end{tabular}

*For measurements of faecal energy, $n=6$.

Conversion-traditional units to SI: energy $1 \mathrm{Kcal} \approx 0.04 \mathrm{MJ}$.

Table 5 Growth measurements in infants on high energy and standard energy feeds (results mean (SD))

\begin{tabular}{|c|c|c|}
\hline & High energy formula $(n=10)$ & Standard energy formula $(n=7)$ \\
\hline Weight gain (g/week) & $250(43) F=7.1 \quad P<0.05$ & $202(32)$ \\
\hline Relative weight gain $(\%)^{*}$ & +51 & +27 \\
\hline Attained weight at 6 weeks $(\mathrm{kg})$ & $4 \cdot 02(0 \cdot 42)$ & $3.75(0.38)$ \\
\hline Attained weight at 3 months (kg) & $5 \cdot 12(0.54)$ & $4.53(0.48)$ \\
\hline Length gain (cm/week) & $0.90(0.07)$ & $0.85(0.08)$ \\
\hline Relative length gain $(\%)^{*}$ & +16.9 & $+16 \cdot 2$ \\
\hline Attained length at 6 weeks $(\mathrm{cm})$ & $53.0(1.9)$ & $52 \cdot 2(2 \cdot 0)$ \\
\hline Attained length at 3 months $(\mathrm{cm})$ & $57 \cdot 1(2 \cdot 3)$ & $56 \cdot 1(2 \cdot 4)$ \\
\hline Head circumference $(\mathrm{cm} /$ week $)$ & $0.53(0.06) \quad F=5.0 \quad P<0.05$ & $0.45(0.09)$ \\
\hline Relative head growth $(\%)^{*}$ & +22 & +17 \\
\hline Attained head circumference at 6 weeks $(\mathrm{cm})$ & $37 \cdot 1(1 \cdot 3)$ & $36 \cdot 5(1 \cdot 2)$ \\
\hline Attained head circumference at 3 months $(\mathrm{cm})$ & $39.4(1.4)$ & $38 \cdot 6(1.4)$ \\
\hline 3-site summed skinfold ( $\mathrm{mm} /$ week) & $0.95(0.44)$ & $0.69(0.42)$ \\
\hline Arm circumference (mm/week) & $0.36(0 \cdot 10)$ & $0.30(0 \cdot 10)$ \\
\hline Abdominal circumference $(\mathrm{cm} /$ week $)$ & $0.86(0.21)$ & $0.78(0.22)$ \\
\hline
\end{tabular}

*See text, Anthropometry.

Growth. Table 5 shows a comparison of growth measurements. Infants fed high energy formula showed marginally better weight gain and head growth $(\mathrm{P}<0.05)$ but there was no difference in any of the other measurements. The mean rate of increase, however, was greater in infants on high energy formula than in those on standard formula in all measurements. When related to standard growth charts, ${ }^{5}$ both groups showed some catch up growth.

Osmolality. There was no difference in the plasma osmolality at 6 weeks of age in the two groups (mean (SD); high energy formula $280 \mathrm{mmol} / \mathrm{kg}$ (27), standard formula $281 \mathrm{mmol} / \mathrm{kg}(17))$.

\section{Discussion}

These findings show that small for gestational age infants regulate their energy intakes but that the regulation is imperfect during the first two months of life. After 2 months of age the regulation of the energy intake seemed quite precise. This points to the development of an appetite control during this period, which can partly be overriden by a high dietary energy concentration. Even in their early weeks, however, the infants showed evidence of constraint on their food intake when fed high energy formula. This does not support the view ${ }^{6}$ that they would, if given the chance, make the most of any opportunity to increase their energy intakes when not limited by volume.

The intakes of our infants on standard energy formula, which were very accurately measured, were much lower at age 2 months than those of the formula fed small for gestational age infants studied by Ounsted and Sleigh, ${ }^{6}$ who apparently consumed about $190 \mathrm{ml} / \mathrm{kg} /$ day at this age, estimated by maternal recall. It is possible that intakes were overestimated in their study, since recall is notoriously unreliable. Another reason for the difference could be the population of infants studied. All Ounsted's infants were more than 2SD below mean weight for gestation at birth and might thus have been predominantly 'asymmetric' or wasted infants who would be expected to show avid feeding and noticeable catch up growth. Our infants, on the other hand, were symmetrically grown and while all being below the 10 th centile, were mainly within the 
$-2 \mathrm{SD}$ limit. Thus they are likely to represent the population of infants who are genetically at the bottom end of the normal range. The fact that they retained more energy and grew faster (showing some catch up growth) during their early weeks when fed high energy formula, indicates that genetic constraints may to some extent be overcome during this period. Whether or not this would be likely to pay dividends in the long term is at present unknown. It was unfortunate that there was a predominance of boys in our high energy formula group and a predominance of girls in the standard energy formula group, since boys grow faster. The high energy formula group, however, gained weight faster in relation to sex specific centiles than did the other group, so the differences between the two groups are more likely to have been due to feeding than to sex.

No similar study has been undertaken in undergrown infants of this age, but Ashworth ${ }^{7}$ studied spontaneous food intake in recovering malnourished children fed on formulas of different energy density. She found that infants given a high energy formula of disguised taste consumed less than they did when offered a low energy formula which tasted similar. The reduced intake, however, did not compensate fully for the higher energy density of the feed, with the result that the net intake of energy was greater on the high energy formula. This was considered an advantage in the circumstances and studies on malnourished infants fed on high energy intakes showed greatly increased rates of skeletal and head growth, as well as increased fat deposition. ${ }^{8}$ Fomon ${ }^{9}$ studied term female infants fed on formulas of differing energy densities and also showed increased energy intakes in the first six weeks on the high energy formula, though in his study the energy densities of the formulas were nearly $100 \%$ different, representing an extreme test of regulation.

The clear evidence of an inherent mechanism for the regulation of energy intake in our infants from the earliest weeks shows that appetite control is present at birth and develops as the infant matures. Hall ${ }^{10}$ proposed that the changing composition of breast milk during feeds was responsible for the development of appetite control. This is obviously not the case in the formula fed infant, who nevertheless does exert a control on intake which is quite precise by age 2 months. Nor can this control be exerted by receptors sensitive to the volume of milk drunk. Our study also makes it certain that regulation is not imposed by alterations in energy absorption, since energy digestibility was the same on low and high energy feeds. It seems most likely that the controlling factors take effect after absorption has occurred.

Until now there have been no data available on energy digestibility in infants nursed at home under normal conditions. Our findings show that by age 6 weeks digestibility has improved from the value of about $80 \%$ found in the first week in term infants (Brooke OG, energy balance data-unpublished) to about $90 \%$, with a small further improvement by 3 months. This change in energy digestibility in the early weeks is likely to be due to maturation of fat digestion. ${ }^{11}$ The increased fat content of the high energy formula did not impose an additional strain on energy absorption, presumably because of the smaller volume of feed consumed.

In conclusion, our study shows that unless high energy feeding is offered at a very young age, which would of course be incompatible with breast feeding, it is unlikely to benefit infants with symmetrical growth retardation, since their ability to control their food intake develops early and seems to limit their net energy intake to a set level. Formula fed infants might, however, achieve useful catch up growth during their first 6 weeks.

This research was supported by Milupa Ltd.

\section{References}

1 Ounsted M, Ounsted C. Postnatal growth. In: On fetal growth rate. London: Heinemann (Spastics International Medical Publications), 1973.

2 Brooke OG, Butters F, Wood C, Bailey P, Tukmachi F. Size at birth from 37-41 weeks gestation: ethnic standards for British infants of both sexes. $J$ Hum Nutr 1981;35:415-30.

${ }^{3}$ Miller DS, Payne PR. A ballistic bomb-calorimeter. Br J Nutr 1975;13:501-8.

4 Tanner JM, Whitehouse RH. Revised standards for triceps and subscapular skinfolds in British children. Arch Dis Child 1975;50:142-5.

5 Gairdner D, Pearson J. A growth chart for premature and other infants. Arch Dis Child 1971;46:783.

6 Ounsted M, Sleigh G. The infant's self-regulation of food intake and weight gain. Lancet 1975;i:1393-7.

7 Ashworth A. Ad lib feeding during recovery from malnutrition. Br J Nutr 1974;31:109-14.

${ }^{8}$ Brooke OG, Wheeler E. High energy feeding in protein-energy malnutrition. Arch Dis Child 1976;51:968-71.

9 Fomon SJ, comp. Voluntary food intake and its regulation. In: Infant nutrition. Philadelphia: W B Saunders, 1974:28-9.

10 Hall B. Changing composition of human milk and early development of an appetite control. Lancet 1975;i:779-81.

11 Grand RJ, Sutphen JL, Montgomery RK. The immature intestine: implications for nutrition of the neonate. In: Elliott $\mathrm{K}$, Whelan J, eds. Development of mammalian absorptive processes. Amsterdam: Excerpta Medica (Ciba Foundation Symposium No 70), 1979.

Correspondence to Dr O G Brooke, St George's Hospital Medical School, Department of Child Health, London SW17 0RE.

Received 11 October $198<$ 